\section{AB1449-HPR PATIENT FACTORS CONTRIBUTING TO AND SHARED DECISION MAKING IN STARTING/SWITCHING BIOLOGICS SPONDYLOARTHRITIS}

E Beckers, Y. van Eijk - Hustings, A. Boonen, A. van Tubergen. Rheumatology, Maastricht University Medical Center, Maastricht, Netherlands

Background: Biologics are effective for treating symptoms in patients (pts) with active spondyloarthritis $(\mathrm{SpA})$ and a number of drugs are available with different working mechanisms, and mode and interval of administration for this indication. Starting/switching a specific biologic occurs for various reasons. It is increasingly advocated to involve pts in treatment decisions. Pts can have various needs and expectations when involved in shared decision making.

Objectives: To explore which pts factors contributed to starting or switching biologics in SpA, how pts experienced shared decision making in this process, and the needs of pts starting biologics.

Methods: Pts with SpA were recruited from the rheumatology department, Maastricht University Medical Centre. In semi-structured focus group interviews pts were asked to elaborate on when and why biologics were started and switched and if they were involved in the treatment decision. A decision aid for rheumatoid arthritis (RA) biologics was shown and pts were asked if they consider a similar decision aid for SpA as valuable. Interviews were audiotaped, transcribed and analysed in NVIVO11 software.

Results: In total, 14 pts with $\mathrm{SpA}$ participated in 4 focus group interviews. Three pts were diagnosed with axial $S p A, 5$ pts with peripheral $\mathrm{SpA}$ and 6 pts were diagnosed with axial- and peripheral SpA, with or without concomitant extra-articular manifestations. Mean age was 62 years (range 41-77 years), 10 were female $(62.5 \%)$. Average time since diagnoses was 28 years. Pts started on average 7.3 years (range 1-14 years) ago with their first biologic. Six pts used 1 biologic, 5 pts had switched once or twice, and 3 pts switched more than 3 times. Factors contributing to starting a first biologic were disease activity, fatigue, intolerance to prior medication, and ineffectiveness of prior medication. Two pts were included in a biological trial. Factors contributing to switching were adverse effects and ineffectiveness of prior biologic.

Most pts were not involved in decision making when biologics were started or could not remember this. Some pts mentioned that only one or limited options were available at the time of start, and that the decision to start was made by the rheumatologist. However, also when more agents became available, decision for a specific biological was often made by the rheumatologist without discussing treatment options.

Pts underlined the importance of how care providers offer a treatment decision. When the decision was offered as a suggestion, "Shall we do.", it was experienced more pleasurable then when the decision was offered as a command, "Let 's do.".

All pts expressed their wish to develop a decision aid in which clear information about each biologic is provided on mode of administration, interval, and effect on different SpA features. One pt explicitly stated that he did not want to be actively involved in decision making, but preferred that the care provider decides.

Conclusions: When involving SpA pts in shared decision making on start/switching of a biological, information on effectiveness on disease activity, fatigue, adverse events as well as expected duration of effectiveness should be provided, in addition to modes of administration and interval of each agent. A decision aid can support pts in this.

Disclosure of Interest: None declared

DOI: 10.1136/annrheumdis-2018-eular.6613

\section{AB1450-HPR COMPARISON OF BIOPSYCHOSOCIAL STATUS OF RHEUMATOID ARTHRITIS AND FIBROMYALGIA PATIENTS}

F.B Oflaz ${ }^{1}$, M. Zahidinova' ${ }^{1}$, G. Arın ${ }^{1}$, N.B. Karaca ${ }^{1}$, S. Apraş Bilgen ${ }^{2}$, E. Ünal ${ }^{1}$. ${ }^{1}$ Department of Physiotherapy and Rehabilitation, Hacettepe University Faculty of Health Sciences; ${ }^{2}$ Department of Internal Medicine-Rheumatology, Hacettepe University Faculty of Medicine, Ankara, Turkey

Background: Rheumatic diseases have biopsychosocial effects on individiuals. ${ }^{1}$ This affection includes the combination of anxiety, depression, and participation in daily living activities. It can be thought that individuals can be affected from different diseases in different ways.

Objectives: The aim of this study is to compare the biopsychosocial status of patients with Rheumatoid Arthritis (RA) and Fibromyalgia (FMS).

Methods: Individuals diagnosed with Rheumatoid Arthritis (RA) and Fibromyalgia (FMS) who applied to the Rheumatology Department of the Medical Faculty of Hacettepe University were included in the study. After the demographic characteristics of the individuals were recorded; daily living activities were assessed with the Health Assessment Questionnaire (HAQ), quality of life with Short Form 36 (SF-36) scale, anxiety and depression levels with Hospital Anxiety and Depression Scale (HADS) and disease related biopsychosocial status with the Cognitive Exercise Therapy Approach Scale (BETY) which is a newly developed scale in rheumatic patients (the authors request that the abbreviation stay as "BETY" as the original in Turkish). ${ }^{2}$

Results: 120 RA and 99 FMS patients were included in the study. The scores of individuals on scales are shown in Table 1. When analysed in terms of differences according to RA and FMS, the anxiety and depression scores of the HADS scale and the SF-36 quality of life scale of the individuals were found to differ between the Physical Functioning, Social Functioning, General Mental Health, Role Limitations Due to Emotional Problems, Vitality Energy or Fatigue and General Health Perception subparametric scores.

Abstract AB1450HPR - Table 1. Comparison of two groups.

\begin{tabular}{lccc}
\hline & RA $(\mathbf{n}=\mathbf{1 2 0})$ & FMS $(\mathbf{n}=\mathbf{9 9})$ & $\mathbf{p}$ \\
\hline Age & 51,91 & $43,03 \pm 8,42$ & $\mathbf{0 , 0 0}$ \\
& $\pm 11,39$ & $27,46 \pm 5,67$ & 0227 \\
BMI & $28,47 \pm 6,55$ & $11,7 \pm 9,47$ & 0229 \\
HAQ & 13,48 & $9,59 \pm 4,82$ & 0000 \\
& $\pm 11,86$ & $9,23 \pm 4,46$ & 0000 \\
HADS-A & $7,07 \pm 5,4$ & $67,14 \pm 22,7$ & 0075 \\
HADS-D & $5,62 \pm 4,39$ & 38,44 & 0046 \\
BETY & 60,64 & $\pm 22,45$ & \\
& $\pm 29,74$ & 20,95 & 0162 \\
SF36-FF & 45,12 & $\pm 34,57$ & 0492 \\
& $\pm 26,09$ & 42,06 & 0008 \\
SF36-FR & 28,54 & $\pm 20,25$ & 0000 \\
& $\pm 43,63$ & $50,63 \pm 25,9$ & \\
SF36-A & 39,87 & 53,87 & 0000 \\
& $\pm 25,76$ & $\pm 20,25$ & 0000 \\
SF36-SI & 36,67 & 30,03 & \\
& $\pm 45,82$ & $\pm 41,83$ & 0000 \\
SF36- & 73,15 & 27,27 & \\
RS & $\pm 19,82$ & $\pm 19,99$ & \\
SF36- & $55,1 \pm 24,91$ & 38,38 & \\
ER & $70,41 \pm 30,4$ & $\pm 16,61$ & \\
SF36- & 50,08 & $\pm 24,76$ &
\end{tabular}

PF: Physical Functioning, RL: Role Limitations, RLE: Role Limitations Due to Emotioal, VEF: Vitality, Energy or Fatigue, GMH: General Mental Health, SF: Social Functioning, P: Pain, GHP: General Health Perception

Conclusions: Physical function, mental health, emotional role strength, energy vitality and general health perception, anxiety and depression levels in RA patients were found to be better than FMS patients. The activities of daily living were thought to be unaffected by the changing parameters of pain and biopsychosocial status.

\section{REFERENCES}

[1] van Middendorp $\mathrm{H}$, Evers AWM. The role of psychological factors in inflammatory rheumatic diseases: From burden to tailored treatment. Best Practice \& Research Clinical Rheumatology. 2016:30(5):932-45.

[2] Ünal E, Arin G, Karaca Nb, Kiraz S, Akdoğan A, Kalyoncu U, et al. Romatizmalı hastalar için bir yaşam kalitesi ölçeğinin geliştirilmesi: madde havuzunun oluşturulması. Journal of Exercise Therapy and Rehabilitation. 2017;4(2):67-75.

Disclosure of Interest: None declared

DOI: 10.1136/annrheumdis-2018-eular.7335

\section{AB1451-HPR BURDEN AMONG CAREGIVERS IN RHEUMATOID ARTHRITIS - A PILOT STUDY}

D. Buitrago-Garcia ${ }^{2}$, I. Mendez ${ }^{1}$, F Rodriguez $^{1}$, L. Villarreal ${ }^{1}$, P. Santos-Moreno ${ }^{3}$. ${ }^{1}$ Health services, Biomab, Center For Rheumatoid Arthritis, Bogota; ${ }^{2}$ Epidemiology, SIIES; ${ }^{3}$ Rheumatology, Biomab, Center For Rheumatoid Arthritis, Bogota, Bogota, Colombia

Background: Rheumatoid arthritis (RA) is a chronic, inflammatory disease of the joints affecting more than $1 \%$ of global population, it is a long term condition that causes pain and disability. ${ }^{1}$ Evidence had shown that 